\title{
Research Article \\ Generalized Hyers-Ulam-Rassias Theorem in Menger Probabilistic Normed Spaces
}

\author{
M. Eshaghi Gordji, ${ }^{1}$ M. B. Ghaemi, ${ }^{2}$ and H. Majani ${ }^{2}$ \\ ${ }^{1}$ Department of Mathematics, Semnan University, P.O. Box 35195-363, Semnan, Iran \\ ${ }^{2}$ Department of Mathematics, Iran University of Science and Technology, Narmak, Tehran, Iran \\ Correspondence should be addressed to M. Eshaghi Gordji, madjid.eshaghi@gmail.com
}

Received 24 September 2009; Accepted 22 January 2010

Academic Editor: Yong Zhou

Copyright (C) 2010 M. Eshaghi Gordji et al. This is an open access article distributed under the Creative Commons Attribution License, which permits unrestricted use, distribution, and reproduction in any medium, provided the original work is properly cited.

We introduce two reasonable versions of approximately additive functions in a Šerstnev probabilistic normed space endowed with $\Pi_{M}$ triangle function. More precisely, we show under some suitable conditions that an approximately additive function can be approximated by an additive mapping in above mentioned spaces.

\section{Introduction and Preliminaries}

Menger proposed transferring the probabilistic notions of quantum mechanic from physics to the underlying geometry. The theory of probabilistic normed spaces (briefly, PN spaces) is important as a generalization of deterministic result of linear normed spaces and also in the study of random operator equations. The theory of probabilistic metric spaces introduced in 1942 by Menger [1], as well as by the authors in [2,3]. The notion of a probabilistic normed space was introduced by Šerstnev [4]. Alsina, Schweizer and Skalar gave a general definition of probabilistic normed space based on the definition of Menger for probabilistic metric spaces in $[5,6]$.

It can be defined, in some way, the class of approximate solutions of the given functional equation one can ask whether each mapping from this class can be somehow approximated by an exact solution of the considered equation. Such a problem was formulated by Ulam in 1940 (cf., [7]) and solved the next year for the Cauchy functional equation by Hyers [8]. In 1950, Aoki [9] and in 1978, Rassias [10] proved a generalization of Hyers' theorem for additive and linear mappings, respectively. 
Theorem 1.1. Let $f$ be an approximately additive mapping from a normed vector space $E$ into a Banach space $F$, that is, $f$ satisfies the inequality

$$
\|f(x+y)-f(x)-f(y)\| \leq \varepsilon\left(\|x\|^{p}+\|y\|^{p}\right)
$$

for all $x, y \in E$, where $\varepsilon$ and $p$ are constants with $\varepsilon>0$ and $0 \leq p<1$. Then the mapping $L: E \rightarrow F$ defined by $L(x)=\lim _{n \rightarrow \infty} 2^{-n} f\left(2^{n} x\right)$ is the unique additive mapping which satisfies

$$
\|f(x)-L(x)\| \leq \frac{2 \varepsilon}{2-2^{p}}\|x\|^{p}
$$

for all $x \in E$.

The result of Rassias has influenced the development of what is now called the HyersUlam-Rassias stability theory for functional equations. In 1994, a generalization of Rassias' theorem was obtained by Găvruţa [11] by replacing the bound $\varepsilon\left(\|x\|^{p}+\|y\|^{p}\right)$ by a general control function $\varphi(x, y)$. Several stability results have been recently obtained for various equations, also for mapping with more general domains and ranges (see [12-18]).

PN spaces were first defined by Šerstnev in 1962 (see [4]). Their definition was generalized in [5]. We recall and apply the definition of probabilistic space briefly as given in [2], together with the notation that will be needed (see [2]). A distance distribution function (briefly, a d.d.f.) is a nondecreasing function $F$ from $\overline{\mathbb{R}}^{+}$into $[0,1]$ that satisfies $F(0)=0$ and $F(+\infty)=1$, and is left-continuous on $(0,+\infty)$; here as usual, $\overline{\mathbb{R}}^{+}:=[0,+\infty]$. The space of d.d.f.'s will be denoted by $\Delta^{+}$; and the set of all $F$ in $\Delta^{+}$for which $\lim _{t \rightarrow+\infty} F(t)=1$ by $D^{+}$. The space $\Delta^{+}$is partially ordered by the usual pointwise ordering of functions, that is, $F \leq G$ if and only if $F(x) \leq G(x)$ for all $x$ in $\overline{\mathbb{R}}^{+}$. For any $a \geq 0, \varepsilon_{a}^{+}$is the d.d.f. given by

$$
\varepsilon_{a}^{+}(t)= \begin{cases}0, & \text { if } t \leq a \\ 1, & \text { if } t>a\end{cases}
$$

The space $\Delta^{+}$can be metrized in several ways [2], but we will here adopt the Sibley metric $d_{S}$. If $F, G$ are d.f.'s and $h$ is in $] 0,1[$, let $(F, G ; h)$ denote the condition:

$$
G(x) \leq F(x+h)+h \quad \forall x \in] 0, \frac{1}{h}[
$$

Then the Sibley metric $d_{S}$ is defined by

$$
d_{S}(F, G):=\inf \{h \in] 0,1[\text { : both }(F, G ; h) \text { and }(G, F ; h) \text { hold }\} \text {. }
$$

In particular, under the usual pointwise ordering of functions, $\varepsilon_{0}$ is the maximal element of $\Delta^{+}$. A triangle function is a binary operation on $\Delta^{+}$, namely a function $\tau: \Delta^{+} \times \Delta^{+} \rightarrow \Delta^{+}$that 
is associative, commutative, nondecreasing in each place and has $\varepsilon_{0}$ as identity, that is, for all $F, G$ and $H$ in $\Delta^{+}$:

$$
\begin{aligned}
& \text { (TF1) } \tau(\tau(F, G), H)=\tau(F, \tau(G, H)), \\
& \text { (TF2) } \tau(F, G)=\tau(G, F), \\
& \text { (TF3) } F \leq G \Rightarrow \tau(F, H) \leq \tau(G, H), \\
& \text { (TF4) } \tau\left(F, \varepsilon_{0}\right)=\tau\left(\varepsilon_{0}, F\right)=F .
\end{aligned}
$$

Moreover, a triangle function is continuous if it is continuous in the metric space $\left(\Delta^{+}, d_{S}\right)$.

Typical continuous triangle functions are $\Pi_{T}(F, G)(x)=\sup _{s+t=x} T(F(s), G(t))$, and $\Pi_{T^{*}}(F, G)=\inf _{s+t=x} T^{*}(F(s), G(t))$. Here $T$ is a continuous $t$-norm, that is, a continuous binary operation on $[0,1]$ that is commutative, associative, nondecreasing in each variable and has 1 as identity; $T^{*}$ is a continuous $t$-conorm, namely a continuous binary operation on $[0,1]$ which is related to the continuous $t$-norm $T$ through $T^{*}(x, y)=1-T(1-x, 1-y)$. For example $T(x, y)=\min (x, y)=M(x, y)$ and $T^{*}(x, y)=\max (x, y)$ or $T(x, y)=\pi(x, y)=x y$ and $T^{*}(x, y)=\pi^{*}(x, y)=x+y-x y$.

Definition 1.2. A Probabilistic Normed space (briefly, PN space) is a quadruple $\left(X, v, \tau, \tau^{*}\right)$, where $X$ is a real vector space, $\tau$ and $\tau^{*}$ are continuous triangle functions with $\tau \leq \tau^{*}$ and $v$ is a mapping (the probabilistic norm) from $V$ into $\Delta^{+}$, such that for every choice of $p$ and $q$ in $V$ the following hold:

(N1) $v_{p}=\varepsilon_{0}$ if and only if $p=\theta(\theta$ is the null vector in $X)$;

(N2) $v_{-p}=v_{p}$;

(N3) $v_{p+q} \geq \tau\left(v_{p}, v_{q}\right)$;

(N4) $v_{p} \leq \tau^{*}\left(v_{\lambda p}, v_{(1-\lambda) p}\right)$ for every $\lambda \in[0,1]$. condition:

A PN space is called a Šerstnev space if it satisfies (N1), (N3) and the following

$$
v_{\alpha p}(x)=v_{p}\left(\frac{x}{|\alpha|}\right)
$$

holds for every $\alpha \neq 0 \in \mathbb{R}$ and $x>0$. When here is a continuous $t$-norm $T$ such that $\tau=\Pi_{T}$ and $\tau^{*}=\Pi_{T^{*}}$, the PN space $\left(X, v, \tau, \tau^{*}\right)$ is called Menger PN space (briefly, MPN space), and is denoted by $(X, v, \tau)$.

Let $(X, v, \tau)$ be an MPN space let $\left\{x_{n}\right\}$ be a sequence in $X$. Then $\left\{x_{n}\right\}$ is said to be convergent if there exists $x \in X$ such that

$$
\lim _{n \rightarrow \infty} \mathcal{v}\left(x_{n}-x\right)(t)=1
$$

for all $t>0$. In this case $x$ is called the limit of $\left\{x_{n}\right\}$.

The sequence $x_{n}$ in MPN space $(X, v, \tau)$ is called Cauchy if for each $\varepsilon>0$ and $\delta>0$, there exists some $n_{0}$ such that $v\left(x_{n}-x_{m}\right)(\delta)>1-\varepsilon$ for all $m, n \geq n_{0}$.

Clearly, every convergent sequence in a MPN space is Cauchy. If each Cauchy sequence is convergent in a MPN space $(X, v, \tau)$, then $(X, v, \tau)$ is called Menger probabilistic Banach space (briefly, MPB space). 
Recently, the stability of functional equations on PN spaces and MPN spaces have been investigated by some authors; see [19-23] and references therein. In this paper, we investigate the stability of additive functional equations on Šerstnev probabilistic normed space endowed with $\Pi_{M}$ triangle function.

\section{Main Results}

We begin our work with uniform version of the Hyers-Ulam-Rassias stability in a Šerstnev PN space in which we uniformly approximate a uniform approximate additive mapping.

Theorem 2.1. Let $X$ be a linear space and $\left(Y, \nu, \Pi_{M}\right)$ be a Šerstnev PB space. Let $\varphi: X \times X \rightarrow[0, \infty)$ be a control function such that

$$
\tilde{\varphi}_{n}(x, y)=\left\{2^{-n-1} \varphi\left(2^{n} x, 2^{n} y\right)\right\} \quad(x, y \in X)
$$

converges to zero. Let $f: X \rightarrow Y$ be a uniformly approximately additive function with respect to $\varphi$ in the sense that

$$
\lim _{t \rightarrow \infty} v(f(x+y)-f(x)-f(y))(t \varphi(x, y))=1
$$

uniformly on $X \times X$. Then $T(x):=\lim _{n \rightarrow \infty} 2^{-n} f\left(2^{n} x\right)$ for any $x \in X$ exists and defines an additive mapping $T: X \rightarrow Y$ such that if for some $\delta>0, \alpha>0$

$$
v(f(x+y)-f(x)-f(y))(\delta \varphi(x, y))>\alpha \quad(x, y \in X)
$$

then

$$
v(T(x)-f(x))\left(\delta \tilde{\varphi}_{n}(x, x)\right)>\alpha \quad(x \in X)
$$

Proof. Given $\varepsilon>0$, by (2.2), we can choose some $t_{0}$ such that

$$
v(f(x+y)-f(x)-f(y))(t \varphi(x, y)) \geq 1-\varepsilon
$$

for all $x, y \in X$ and all $t \geq t_{0}$. Putting $y=x$ in (2.5) we get

$$
v(f(2 x)-2 f(x))(t \varphi(x, x)) \geq 1-\varepsilon
$$

and by replacing $x$ by $2^{n} x$, we obtain

$$
v\left(2^{-n-1} f\left(2^{n+1} x\right)-2^{-n} f\left(2^{n} x\right)\right)\left(t 2^{-n-1} \varphi\left(2^{n} x, 2^{n} x\right)\right) \geq 1-\varepsilon .
$$

By passing to a nonincreasing subsequence, if necessary, we may assume that $\left\{2^{-n-1} \varphi\left(2^{n} x, 2^{n} y\right)\right\}$ is nonincreasing. 
Thus for each $n>m$ we have

$$
\begin{aligned}
& v\left(2^{-m} f\left(2^{m} x\right)-2^{-n} f\left(2^{n} x\right)\right)\left(t 2^{-m-1} \varphi\left(2^{m} x, 2^{m} x\right)\right) \\
& =v\left(\sum_{k=m}^{n-1}\left(2^{-k} f\left(2^{k} x\right)-2^{-k-1} f\left(2^{k+1} x\right)\right)\right)\left(t 2^{-m-1} \varphi\left(2^{m} x, 2^{m} x\right)\right) \\
& \geq \Pi_{M}\left\{v\left(2^{-m} f\left(2^{m} x\right)-2^{-m-1} f\left(2^{m+1} x\right)\right)\right. \\
& \left.\geq\left(\sum_{k=m+1}^{n-1}\left(2^{-k} f\left(2^{k} x\right)-2^{-k-1} f\left(2^{k+1} x\right)\right)\right)\right\}\left(t 2^{-m-1} \varphi\left(2^{m} x, 2^{m} x\right)\right) \\
& v \Pi_{M}\left\{1-\varepsilon, \Pi_{M}\left\{v\left(2^{-m-1} f\left(2^{m+1} x\right)-2^{-m-2} f\left(2^{m+2} x\right)\right),\right.\right. \\
& \left.\left.\left.\sum_{k=m+2}^{n-1}\left(2^{-k} f\left(2^{k} x\right)-2^{-k-1} f\left(2^{k+1} x\right)\right)\right)\right\}\left(t 2^{-m-2} \varphi\left(2^{m+1} x, 2^{m+1} x\right)\right)\right\}
\end{aligned}
$$

$\geq 1-\varepsilon$.

The convergence of (2.1) implies that for given $\delta>0$ there is $n_{0} \in \mathbb{N}$ such that

$$
t_{0} 2^{-n-1} \varphi\left(2^{n} x, 2^{n} x\right)<\delta \quad \forall n \geq n_{0}
$$

Thus by (2.8) we deduce that

$$
\begin{aligned}
& v\left(2^{-m} f\left(2^{m} x\right)-2^{-n} f\left(2^{n} x\right)\right)(\delta) \\
& \quad \geq v\left(2^{-m} f\left(2^{m} x\right)-2^{-n} f\left(2^{n} x\right)\right)\left(t_{0} 2^{-m-1} \varphi\left(2^{m} x, 2^{m} x\right)\right) \geq 1-\varepsilon
\end{aligned}
$$

for each $n \geq n_{0}$. Hence $2^{-n} f\left(2^{n} x\right)$ is a Cauchy sequence in $Y$. Since $\left(Y, v, \Pi_{M}\right)$ is complete, this sequence converges to some $T(x) \in Y$. Therefore, we can define a mapping $T: X \rightarrow Y$ by $T(x):=\lim _{n \rightarrow \infty} 2^{-n} f\left(2^{n} x\right)$, namely, for each $t>0$, and $x \in X$,

$$
v\left(T(x)-2^{-n} f\left(2^{n} x\right)\right)(t)=1
$$


Next, let $x, y \in X$. Temporarily fix $t>0$ and $0<\varepsilon<1$. Since $2^{-n-1} \varphi\left(2^{n} x, 2^{n} y\right)$ converges to zero, there is some $n_{1}>n_{0}$ such that $t_{0} \varphi\left(2^{n} x, 2^{n} y\right)<t 2^{n+1}$ for all $n \geq n_{1}$. Hence for each $n \geq n_{1}$, we have

$$
\begin{gathered}
v(T(x+y)-T(x)-T(y))(t) \\
\geq \Pi_{M}\left\{\Pi_{M}\left\{v\left(T(x+y)-2^{-n-1} f\left(2^{n+1}(x+y)\right)\right)(t), v\left(T(x)-2^{-n-1} f\left(2^{n+1} x\right)\right)(t)\right\},\right. \\
\Pi_{M}\left\{v\left(T(y)-2^{-n-1} f\left(2^{n+1} y\right)\right)(t),\right. \\
\left.\left.v\left(f\left(2^{n+1}(x+y)\right)-f\left(2^{n+1} x\right)-f\left(2^{n+1} y\right)\right)\left(2^{n+1} t\right)\right\}\right\}
\end{gathered}
$$

but we have

$$
\begin{aligned}
& \lim _{n \rightarrow \infty} v\left(T(x+y)-2^{-n-1} f\left(2^{n+1}\right)\right)(t)=1, \\
& \lim _{n \rightarrow \infty} v\left(T(x)-2^{-n-1} f\left(2^{n+1} x\right)\right)(t)=1 \\
& \lim _{n \rightarrow \infty} v\left(T(y)-2^{-n-1} f\left(2^{n+1} y\right)\right)(t)=1
\end{aligned}
$$

and by (2.5) and for large enough $n$, we have

$$
\begin{aligned}
& v\left(f\left(2^{n+1}(x+y)\right)-f\left(2^{n+1} x\right)-f\left(2^{n+1} y\right)\right)\left(2^{n+1} t\right) \\
& \quad \geq v\left(f\left(2^{n+1}(x+y)\right)-f\left(2^{n+1} x\right)-f\left(2^{n+1} y\right)\right)\left(t_{0} \varphi\left(2^{n} x, 2^{n} y\right)\right) \geq 1-\varepsilon .
\end{aligned}
$$

Thus

$$
v(T(x+y)-T(x)-T(y))(t) \geq 1-\varepsilon \quad \forall t>0,0<\varepsilon<1 .
$$

It follows that $v(T(x+y)-T(x)-T(y))(t)=1$ for all $t>0$ and by $(\mathrm{N} 1)$, we have $T(x+y)=$ $T(x)+T(y)$.

To end the proof, let, for some positive $\delta$ and $\alpha,(2.3)$ hold. Let $x \in X$. Putting $m=0$ and $\alpha=1-\varepsilon$ in (2.10), we get

$$
v\left(f\left(2^{n} x\right)-2^{n} f(x)\right)(\delta) \geq \alpha
$$

for all positive integers $n \geq n_{0}$. Thus for large enough $n$, we have

$$
\begin{aligned}
& v(f(x)-T(x))\left(\delta 2^{-n-1} \varphi\left(2^{n} x, 2^{n} x\right)\right) \\
& \quad \geq \Pi_{M}\left\{v\left(f(x)-2^{-n} f\left(2^{n} x\right)\right), v\left(2^{-n} f\left(2^{n} x\right)-T(x)\right)\right\}\left(\delta 2^{-n-1} \varphi\left(2^{n} x, 2^{n} x\right)\right) \geq \alpha
\end{aligned}
$$


therefore

$$
v(T(x)-f(x))\left(\delta \tilde{\varphi}_{n}(x, x)\right)>\alpha
$$

Corollary 2.2. Let $X$ be a linear space and $\left(Y, \nu, \Pi_{M}\right)$ be a Šerstnev PB space. Let $\varphi: X \times X \rightarrow[0, \infty)$ be a control function satisfying (2.2). Let $f: X \rightarrow Y$ be a uniformly approximately additive function with respect to $\varphi$. Then there is a unique additive mapping $T: X \rightarrow Y$ such that

$$
\lim _{n \rightarrow \infty} \mathcal{v}(f(x)-T(x))\left(t \tilde{\varphi}_{n}(x, x)\right)=1
$$

uniformly on X.

Proof. The existence of uniform limit (2.19) immediately follows from Theorem 2.1. It remains to prove the uniqueness assertion.

Let $S$ be another additive mapping satisfying (2.19). Fix $c>0$. Given $\varepsilon>0$, by (2.19) for $T$ and $S$, we can find some $t_{0}>0$ such that

$$
\begin{aligned}
& v(f(x)-T(x))\left(t \tilde{\varphi}_{n}(x, x)\right) \geq 1-\varepsilon \\
& v(f(x)-S(x))\left(t \tilde{\varphi}_{n}(x, x)\right) \geq 1-\varepsilon
\end{aligned}
$$

for all $x \in X$ and $t \geq t_{0}$. Fix some $x \in X$ and find some integer $n_{0}$ such that

$$
t_{0} 2^{-n} \varphi\left(2^{n+1} x, 2^{n+1}\right)<c \quad \forall n \geq n_{0}
$$

Then we have

$$
\begin{aligned}
v(S(x) & -T(x))(c) \\
& \geq \Pi_{M}\left\{v\left(2^{-n} f\left(2^{n} x\right)-T(x)\right), v\left(S(x)-2^{-n} f\left(2^{n} x\right)\right)\right\}(c) \\
& =\Pi_{M}\left\{v\left(f\left(2^{n} x\right)-T\left(2^{n} x\right)\right), v\left(S\left(2^{n} x\right)-f\left(2^{n} x\right)\right)\right\}\left(2^{n} c\right) \\
& \geq \Pi_{M}\left\{v\left(f\left(2^{n} x\right)-T\left(2^{n} x\right)\right), v\left(S\left(2^{n} x\right)-f\left(2^{n} x\right)\right)\right\}\left(t_{0} \varphi\left(2^{n+1} x, 2^{n+1} x\right)\right) \\
& \geq 1-\varepsilon .
\end{aligned}
$$

It follows that $v(S(x)-T(x))(c)=1$ for all $c>0$. Thus $T(x)=S(x)$ for all $x \in X$.

Considering the control function $\varphi(x, y)=\theta\left(\|x\|^{q}+\|y\|^{q}\right)$ for some $\theta>0$, we obtain the following.

Corollary 2.3. Let $X$ be a normed linear space. Let $\left(Y, v, \Pi_{M}\right)$ be a Šerstnev PB space. Let $\theta \geq 0$ and $0 \leq q<1$. Suppose that $f: X \rightarrow Y$ is a function such that

$$
\lim _{t \rightarrow \infty} v(f(x+y)-f(x)-f(y))\left(t \theta\left(\|x\|^{q}+\|y\|^{q}\right)\right)=1
$$


uniformly on $X \times X$. Then there is a unique additive mapping $T: X \rightarrow Y$ such that

$$
\lim _{t \rightarrow \infty} v(T(x)-f(x))\left(t 2^{n(q-1)} \theta\|x\|^{q}\right)=1
$$

uniformly on X.

We are ready to give our nonuniform version of the Hyers-Ulam-Rassias theorem in Šerstnev PN spaces.

Theorem 2.4. Let $X$ be a linear space. Let $(Z, \omega, \Pi M)$ be a Šerstnev MPN space. Let $\psi: X \times X \rightarrow Z$ be a function such that for some $0<\alpha<2$,

$$
\omega(\psi(2 x, 2 y))(t) \geq \omega(\alpha \psi(x, y))(t)
$$

for all $x, y \in X$ and $t>0$. Let $\left(Y, v, \Pi_{M}\right)$ be a Šerstnev PB space and let $f: X \rightarrow Y$ be a $\psi$ approximately additive mapping in the sense that

$$
v(f(x+y)-f(x)-f(y))(t) \geq \omega(\psi(x, y))(t)
$$

for each $t>0$ and $x, y \in X$. Then there exists unique additive mapping $T: X \rightarrow Y$ such that

$$
v(f(x)-T(x))(t) \geq \omega\left(\frac{1}{2} \psi(x, x)(t)\right)
$$

where $x \in X$ and $t>0$.

Proof. Put $y=x$ in (2.26) to obtain

$$
v(f(2 x)-2 f(x))(t) \geq \omega(\psi(x, x))(t) \quad(x \in X, t>0) .
$$

Using (2.25) and induction on $n$, one can verify that

$$
\omega\left(\psi\left(2^{n} x, 2^{n}\right) x\right)(t) \geq \omega\left(\alpha^{n} \psi(x, x)\right)(t)
$$

for all $x \in X$ and $t>0$. Replacing $x$ by $2^{n-1} x$ in (2.28) and using (2.29) we get

$$
v\left(f\left(2^{n} x\right)-2 f\left(2^{n-1} x\right)\right)(t) \geq \omega\left(\alpha^{n-1} \psi(x, x)\right)(t)
$$

for all $x \in X$ and $t>0$. It follows from (2.30) that

$$
v\left(2^{-n} f\left(2^{n} x\right)-2^{-n+1} f\left(2^{n-1} x\right)\right)\left(2^{-n} t\right) \geq \omega\left(\left(\frac{1}{\alpha}\right) \psi(x, x)\right)\left(\alpha^{-n} t\right)
$$


whence

$$
v\left(2^{-n} f\left(2^{n} x\right)-2^{-n+1} f\left(2^{n-1} x\right)\right)\left(\left(\frac{\alpha^{n}}{2^{n}}\right) t\right) \geq \omega\left(\left(\frac{1}{\alpha}\right) \psi(x, x)\right)(t)
$$

for all $n>m \geq 0, x \in X$ and $t>0$. So

$$
\begin{aligned}
v\left(2^{-n} f\left(2^{n} x\right)-2^{-m} f\left(2^{m} x\right)\right)\left(\left(\frac{\alpha^{m+1}}{2^{m+1}}\right) t\right) \\
\quad=v\left(\sum_{k=m+1}^{n} 2^{-k} f\left(2^{k} x\right)-2^{-k+1} f\left(2^{k-1} x\right)\right)\left(\left(\frac{\alpha^{m+1}}{2^{m+1}}\right) t\right) \\
\quad \geq \omega\left(\left(\frac{1}{\alpha}\right) \psi(x, x)\right)(t)
\end{aligned}
$$

whence

$$
v\left(2^{-n} f\left(2^{n} x\right)-2^{-m} f\left(2^{m} x\right)\right)(t) \geq \omega\left(\frac{1}{\alpha} \psi(x, x)\right)\left(\left(\frac{\alpha^{m+1}}{2^{m+1}}\right) t\right)
$$

for all $n>m \geq 0, x \in X$ and $t>0$. Fix $x \in X$. By

$$
\lim _{s \rightarrow \infty} \omega\left(\frac{1}{\alpha} \psi(x, x)\right)(s)=1
$$

we deduce that $\left\{2^{-n} f\left(2^{n} x\right)\right\}$ is a Cauchy sequence in $\left(Y, \nu, \Pi_{M}\right)$. Since $\left(Y, v, \Pi_{M}\right)$ is complete, this sequence converges to some point $T(x) \in Y$. It follows from (2.26) that

$$
\begin{aligned}
v\left(f\left(2^{n}(x+y)\right)-f\left(2^{n} x\right)-f\left(2^{n} y\right)\right)(t) & \geq \omega\left(\psi\left(2^{n} x, 2^{n} y\right)\right)(t) \\
& \geq \omega\left(\alpha^{n} \psi(x, y)\right)(t) \\
& \geq \omega(\psi(x, y))\left(\alpha^{-n} t\right)
\end{aligned}
$$

whence

$$
v\left(2^{-n} f\left(2^{n}(x+y)\right)-2^{-n} f\left(2^{n} x\right)-2^{-n} f\left(2^{n} y\right)\right)(t) \geq \omega(\psi(x, y))\left(\left(\frac{2}{\alpha}\right)^{n} t\right) .
$$

We have

$$
\begin{aligned}
& v(T(x+y)-T(x)-T(y))(t) \\
& \geq \Pi_{M}\left\{\Pi_{M}\left\{v\left(T(x+y)-2^{-n} f\left(2^{n}(x+y)\right)\right), v\left(T(x)-2^{-n} f\left(2^{n} x\right)\right)\right\}(t),\right. \\
& \left.\quad \Pi_{M}\left\{v\left(T(y)-2^{-n} f\left(2^{n} y\right)\right), v\left(2^{-n} f\left(2^{n}(x+y)\right)-2^{-n} f\left(2^{n} x\right)-2^{-n} f\left(2^{n} y\right)\right)\right\}(t)\right\} .
\end{aligned}
$$


By (2.37) and the fact that

$$
\lim _{n \rightarrow \infty} v\left(T(z)-2^{-n} f\left(2^{n} z\right)\right)=1
$$

for all $z \in X$ and $r>0$, each term on the right-hand side tends to 1 as $n \rightarrow \infty$. Hence

$$
v(T(x+y)-T(x)-T(y))(t)=1
$$

By (N1), it means that

$$
T(x+y)=T(x)+T(y) .
$$

Furthermore, let $x \in X$ and $t>0$. Using (2.34) with $m=0$ we obtain

$$
\begin{aligned}
& v(T(x)-f(x))(t) \\
& \quad \geq \Pi_{M}\left\{v\left(T(x)-2^{-n} f\left(2^{n} x\right)\right), v\left(2^{-n} f\left(2^{n} x\right)-f(x)\right)\right\}(t) \\
& \quad \geq \Pi_{M}\left\{v\left(T(x)-2^{-n} f\left(2^{n} x\right)\right), \omega\left(\left(\frac{1}{2}\right) \psi(x, x)\right)\right\}(t) .
\end{aligned}
$$

Hence

$$
\begin{aligned}
v(T(x) & -f(x))(t) \\
\geq & \Pi_{M}\left\{\lim _{n \rightarrow \infty} v\left(T(x)-2^{-n} f\left(2^{n} x\right)\right), \omega\left(\left(\frac{1}{2}\right) \psi(x, x)\right)\right\}(t) \\
= & \omega\left(\left(\frac{1}{2}\right) \psi(x, x)\right)(t) .
\end{aligned}
$$

The uniqueness of $T$ can be proved in a similar fashion as in the proof of Corollary 2.2.

\section{References}

[1] K. Menger, "Statistical metrics," Proceedings of the National Academy of Sciences of the United States of America, vol. 28, pp. 535-537, 1942.

[2] B. Schweizer and A. Sklar, Probabilistic Metric Spaces, North-Holland Series in Probability and Applied Mathematics, North-Holland, New York, NY, USA, 1983.

[3] B. Schweizer and A. Sklar, "Statistical metric spaces," Pacific Journal of Mathematics, vol. 10, pp. 313$334,1960$.

[4] A. N. Šerstnev, "On the motion of a random normed space," Doklady Akademii Nauk SSSR, vol. 149, no. 2, pp. 280-283, 1963, English translation in Soviet Mathematics. Doklady, vol. 4, pp. 388-390, 1963.

[5] C. Alsina, B. Schweizer, and A. Sklar, "On the definition of a probabilistic normed space," Aequationes Mathematicae, vol. 46, no. 1-2, pp. 91-98, 1993.

[6] C. Alsina, B. Schweizer, and A. Sklar, "Continuity properties of probabilistic norms," Journal of Mathematical Analysis and Applications, vol. 208, no. 2, pp. 446-452, 1997.

[7] S. M. Ulam, Problems in Modern Mathematics, Science editions, John Wiley \& Sons, New York, NY, USA, 1964, chapter VI, some questions in Analysis. 
[8] D. H. Hyers, "On the stability of the linear functional equation," Proceedings of the National Academy of Sciences of the United States of America, vol. 27, pp. 222-224, 1941.

[9] T. Aoki, "On the stability of the linear transformation in Banach spaces," Journal of the Mathematical Society of Japan, vol. 2, pp. 64-66, 1950.

[10] Th. M. Rassias, "On the stability of the linear mapping in Banach spaces," Proceedings of the American Mathematical Society, vol. 72, no. 2, pp. 297-300, 1978.

[11] P. Găvruţa, "A generalization of the Hyers-Ulam-Rassias stability of approximately additive mappings," Journal of Mathematical Analysis and Applications, vol. 184, no. 3, pp. 431-436, 1994.

[12] C. Baak and M. S. Moslehian, "On the stability of $J^{*}$-homomorphisms," Nonlinear Analysis: Theory, Methods $\mathcal{E}$ Applications, vol. 63, no. 1, pp. 42-48, 2005.

[13] S. Czerwik, Functional Equations and Inequalities in Several Variables, World Scientific, River Edge, NJ, USA, 2002.

[14] R. Farrokhzad and S. A. R. Hosseinioun, "Perturbations of Jordan higher derivations in Banach ternary algebras: an alternative fixed point approach," International Journal of Nonlinear Analysis and Applications, vol. 1, no. 1, pp. 42-53, 2010.

[15] N. Ghobadipour and C. Park, "Cubic-quartic functional equations in fuzzy normed spaces," International Journal of Nonlinear Analysis and Applications, vol. 1, no. 1, pp. 12-21, 2010.

[16] D. H. Hyers, G. Isac, and Th. M. Rassias, Stability of Functional Equations in Several Variables, vol. 34 of Progress in Nonlinear Differential Equations and Their Applications, Birkhäuser, Boston, Mass, USA, 1998.

[17] S.-M. Jung, Hyers-Ulam-Rassias Stability of Functional Equations in Mathematical Analysis, Hadronic Press, Palm Harbor, Fla, USA, 2001.

[18] H. Khodaei and Th. M. Rassias, "Approximately generalized additive functions in several variables," International Journal of Nonlinear Analysis and Applications, vol. 1, no. 1, pp. 22-41, 2010.

[19] M. Eshaghi Gordji and M. B. Savadkouhi, "Stability of mixed type cubic and quartic functional equations in random normed spaces," Journal of Inequalities and Applications, vol. 2009, Article ID 527462, 9 pages, 2009.

[20] M. Eshaghi Gordji, M. B. Savadkouhi, and C. Park, "Quadratic-quartic functional equations in RNspaces," Journal of Inequalities and Applications, vol. 2009, Article ID 868423, 14 pages, 2009.

[21] M. Eshaghi Gordji, J. M. Rassias, and M. B. Savadkouhi, "Approximation of the quadratic and cubic functional equations in RN-spaces," European Journal of Pure and Applied Mathematics, vol. 2, no. 4, pp. 494-507, 2009.

[22] A. Ghaffari, A. Alinejad, and M. E. Gordji, "On the stability of general cubic-quartic functional equations in Menger probabilistic normed spaces," Journal of Mathematical Physics, vol. 50, no. 12, Article ID 123301, 7 pages, 2009.

[23] S. Shakeri, R. Saadati, Gh. Sadeghi, and S. M. Vaezpour, "Stability of the cubic functional equation in menger probabilistic normed spaces," Journal of Applied Sciences, vol. 9, no. 9, pp. 1795-1797, 2009. 


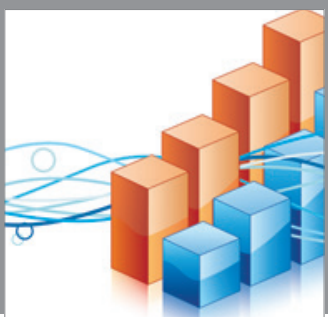

Advances in

Operations Research

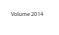

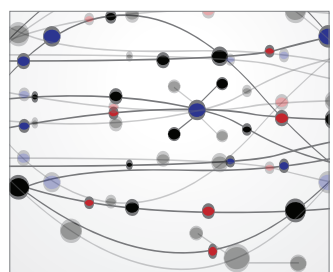

\section{The Scientific} World Journal
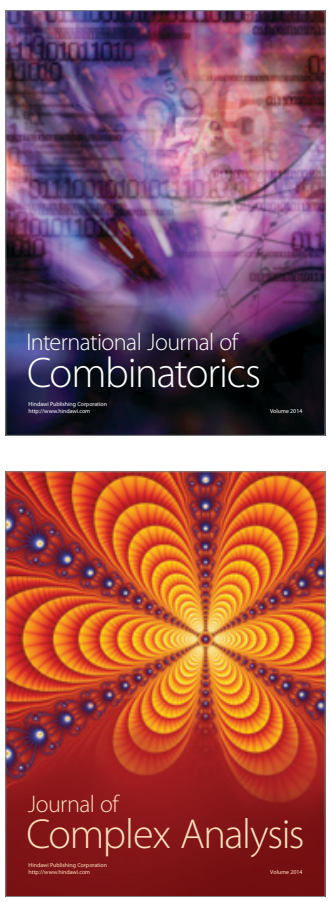

International Journal of

Mathematics and

Mathematical

Sciences
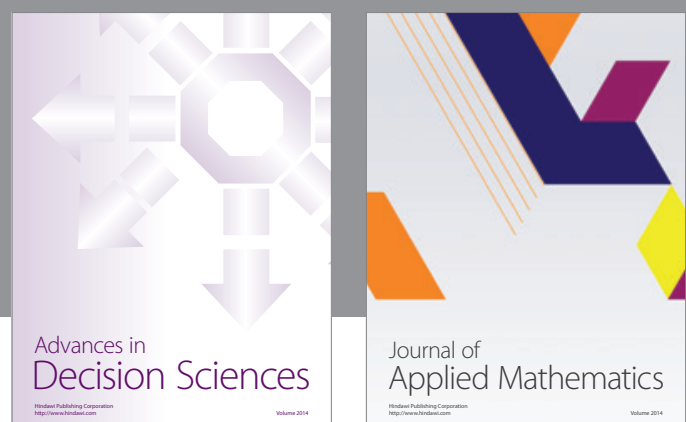

Journal of

Applied Mathematics
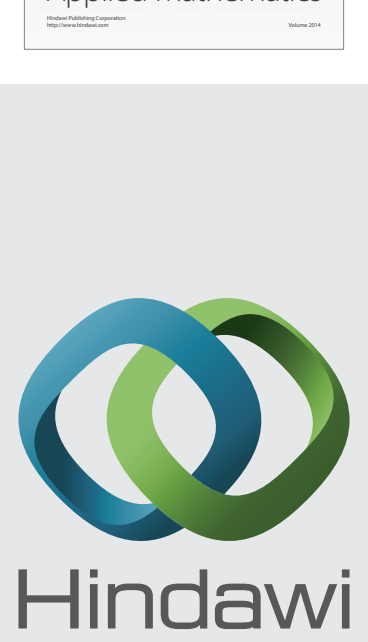

Submit your manuscripts at http://www.hindawi.com
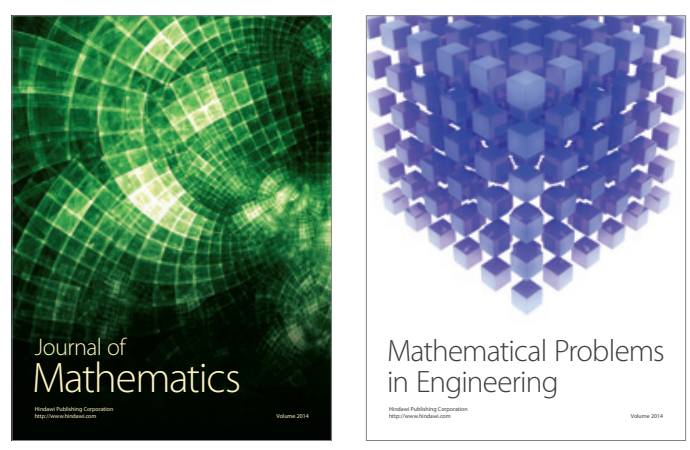

Mathematical Problems in Engineering
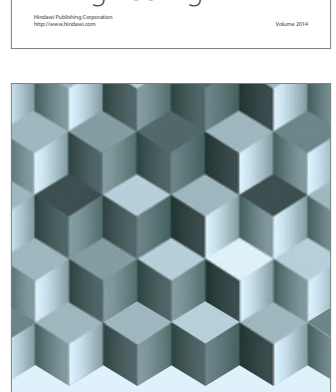

Journal of

Function Spaces
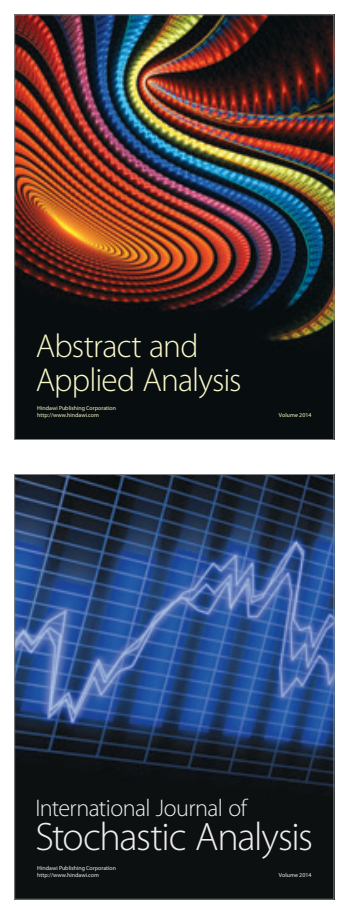

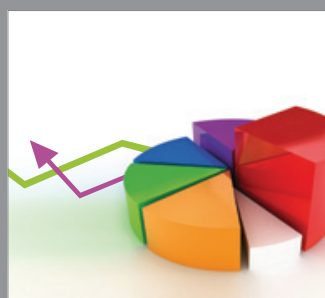

ournal of

Probability and Statistics

Promensencen
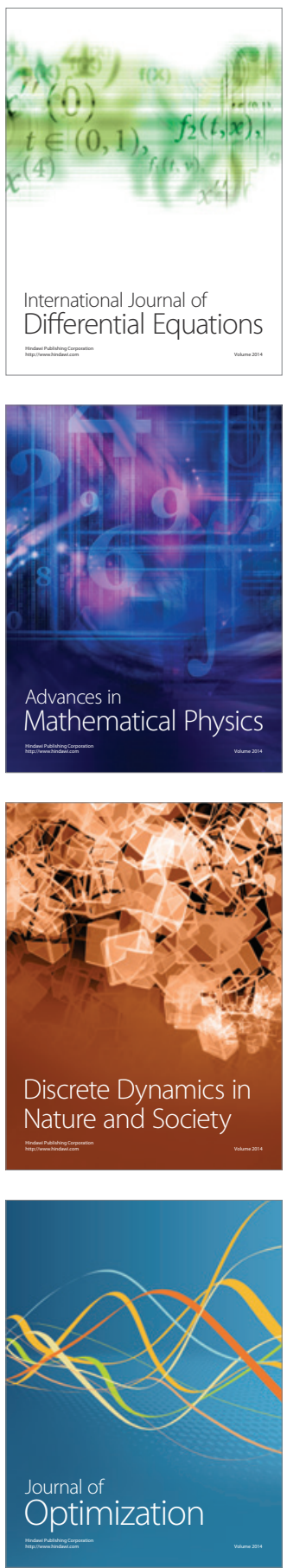